\title{
Color Rendering Index Thermal Stability Improvement of Glass-Based Phosphor-Converted White Light-Emitting Diodes for Solid-State Lighting
}

\author{
Chun-Chin Tsai \\ Department of Optoelectronic Engineering, Far East University, Tainan 744, Taiwan \\ Correspondence should be addressed to Chun-Chin Tsai; tsaichunchin@gmail.com
}

Received 29 January 2014; Revised 18 March 2014; Accepted 1 April 2014; Published 5 June 2014

Academic Editor: Ray-Hua Horng

Copyright (c) 2014 Chun-Chin Tsai. This is an open access article distributed under the Creative Commons Attribution License, which permits unrestricted use, distribution, and reproduction in any medium, provided the original work is properly cited.

High color rendering index performance has been required for phosphor-converted warm-white light-emitting diodes (PCWWLEDs) in lighting industry. The characteristics of low-temperature fabricated phosphor (yellow: $\mathrm{Ce}^{3+}: \mathrm{YAG}_{\mathrm{G}}$ green: $\mathrm{Tb}^{3+}: \mathrm{YAG}$, and red: $\mathrm{CaAlClSiN}_{3}: \mathrm{Eu}^{2+}$ ) doped glass were presented for applications to high color rendering index warm-white-light-emitting diodes. Color coordinates $(x, y)=(0.36,0.29)$, quantum yield $(\mathrm{QY})=55.6 \%$, color rending index $(\mathrm{CRI})=85.3$, and correlated color temperature $(C C T)=3923 \mathrm{~K}$ were characterized. Glass-based PC-WWLEDs was found able to maintain good thermal stability for long-time high-temperature operation. QY decay, CRI remenance, and chromaticity shift were also analyzed for glass- and siliconebased high-power PC-WLEDs by thermal aging at $150^{\circ} \mathrm{C}$ and $250^{\circ} \mathrm{C}$ for industrial test standard's aging time 1008 hours. Better than the silicone's, thermal stability of glass-based PC-WLEDs has been improved. The resulted high color rendering index (CRI) glass phosphor potentially can be used as a phosphor layer for high-performance and low-cost PC-WLEDs used in next-generation indoor solid-state lighting applications.

\section{Introduction}

For liquid crystal displays and outdoor lightings, white lightemitting diodes (WLEDs) have been extensively used as backlight source due to their eco-friendly features, compact size, and high reliability compared to conventional light sources, such as incandescent bulbs and fluorescent lamps [1-4]. The so-called "white light" emission can be typically generated by the mixture of three primary colors (red, green, and blue) or two complimentary colors (e.g., blue and yellow), based on the principle of additive color mixing [57]. Subjected to the physical structure of WLED modules, the strategy of realizing white light can be categorized into two major technologies: (1) combination of multiple LEDs and (2) phosphor-converted LEDs (PC-LEDs). In the first strategy of white light emission, two or three monochromatic LEDs are used to generate preferred white light. Dynamic color control is achievable by electronically adjusting the driving current of each LED individually. Its high quantum efficiency is also an advantage of the multiple LEDs technique without
Stokes shift which is due to photonic energy downconversion $[8,9]$. However, cost of multiple LEDs technique is much higher than other techniques, so multiple LEDs technique is only used in some special applications. Therefore, PCLEDs technology dominates the market today because of significantly low cost, compact structure, and simple driving circuit, although the quantum efficiency of PC-LEDs is slightly lower than that of multiple LEDs. PC-LEDs are in a configuration with a short-wavelength-emitting LED as the excitation sources in the visible $[10,11]$ and/or UV $[12$, 13] spectral regimes, and a wavelength converter such as phosphor, which converts the light from excitation sources to generate white light. The correlated color temperature and color rendering property of the PC-LEDs can be determined upon the composition and concentration of the phosphor in the wavelength converters. Full development of phosphor materials significantly contributed to LED lightings. Yellow phosphors, such as broadband YAG phosphors, have been extensively studied on the integration with the complementary blue LEDs to form white light. However, color rendering 


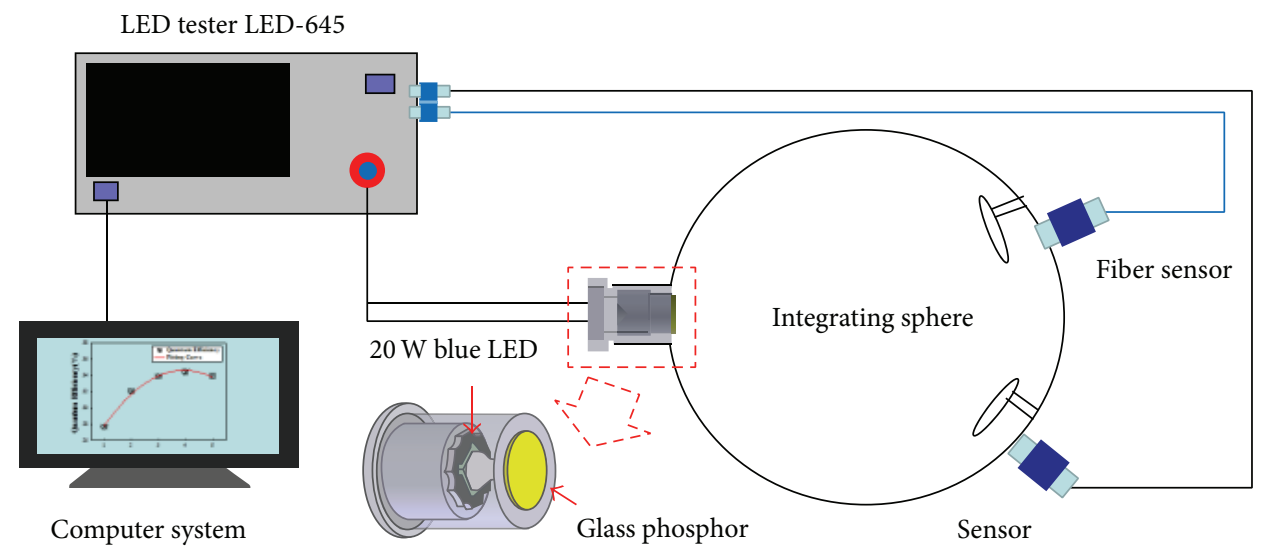

FIgURE 1: The test chamber schematic for optical measurement.

index (CRI) of the WLEDs is usually less than 70, which is not acceptable for general interior illumination and some special lighting including medical applications and architectural lighting. To achieve high color rendering properties, multiphosphors such as red/yellow and orange/yellow have to be added into the color conversion layer. Multiphosphor-doped silicone as the color conversion layer of the high-CRI WLED has been fabricated to demonstrate the above purpose $[14,15]$, but the poor thermal stability of the silicone matrix weakens the superiority for high-luminance lighting applications, due to the lower glass transition temperature of silicone $\left(150^{\circ} \mathrm{C}\right)$. In the previous works for yellow light emission to mix with blue light from LED, we have demonstrated novel glass-based phosphors with excellent thermal stability for the applications of high-power WLEDs [16], but the resulted CRI values were normally as low as 70s with single phosphor powder.

Remote phosphor was studied as an alternative technology for white light LED. Kuo et al. investigated patterned structure of remote phosphor for phosphor-converted white light LEDs [17]. This patterned structure was designed to reduce the angular-dependent correlated color temperature (CCT). Intematix Company reported polycarbonate-based remote phosphor layer around source LED [18], though glassbased remote phosphor product could be under development.

In this study, we fabricated a thermally stable multiphosphor-doped glass (MPDG) for the goal. The results showed that the glass-based PC-WLEDs exhibited good thermal stability in lumen loss, chromaticity shift, CRI, and QE characteristics. Then we compared with the siliconebased high-power PC-WLEDs under thermal aging at lower temperature of $150^{\circ} \mathrm{C}, 250^{\circ} \mathrm{C}, 350^{\circ} \mathrm{C}$, and $450^{\circ} \mathrm{C}$. The results demonstrated that the thermal stability of glass-based PCWLEDs outperformed the silicone-based PC-WLEDs. The novel development of glass-based PC-WLEDs is essentially critical to the application of LED modules in the area where absolute reliability is required and where silicone simply cannot stand the heat, humidity, or other deteriorating factors due to its low thermal stability. The multiphosphors layer of glass as an encapsulating material may be advanced for many applications where the LED modules with high reliability are required.

\section{Experiment and Measurement}

The glass matrix was composed of $\mathrm{SiO}_{2}, \mathrm{Na}_{2} \mathrm{CO}_{3}, \mathrm{Al}_{2} \mathrm{O}_{3}$, and $\mathrm{CaO}$ to be mixed and then melt at $1300^{\circ} \mathrm{C}$ for 1 hour in a platinum crucible. The cooled cullet glass $\left(\mathrm{SiO}_{2}-\mathrm{Na}_{2} \mathrm{O}-\right.$ $\mathrm{Al}_{2} \mathrm{O}_{3}-\mathrm{CaO}$ ) was milled into powders and kept dried. Yellow $\left(\mathrm{Y}_{3} \mathrm{Al}_{5} \mathrm{O}_{12}: \mathrm{Ce}^{3+}\right.$, YAG based $)$, green $\left(\mathrm{Lu}_{3} \mathrm{Al}_{5} \mathrm{O}_{12}: \mathrm{Ce}^{3+}\right.$, LuAG based), and red ( $\mathrm{CaAlSiN}_{3}: \mathrm{Eu}^{2+}$, nitride based) phosphors of different ratio were uniformly mixed into the matrix glass powder followed by melting at $680^{\circ} \mathrm{C}$ for 6 hours, labeled as $Y_{1} G_{0} R_{0} D G, Y_{1} G_{1} R_{1} D G, Y_{2} G_{1} R_{1} D G, Y_{1} G_{2} R_{1} D G$, and $Y_{1} G_{1} R_{2} D G$ according to the composition ratio among yellow/green/red phosphor in the glass phosphors. These glass phosphor samples were then polished to $0.5 \mathrm{~mm}$ of thickness after quenching down to room temperature. With $15 \mathrm{~mm}$ in diameter and $0.5 \mathrm{~mm}$ thick, the solidified glass phosphor circular disks were entirely covered over the LED and the reflective cup to form a WLED module. An integrating sphere equipped with an optical fiber and a CCD detector was employed to measure the optical spectra of the WLED module.

For thermal aging tests (its setup as shown in Figure 1), eleven phosphor disk samples from low-temperature glass CeYDG were aging at $150^{\circ} \mathrm{C}, 250^{\circ} \mathrm{C}, 350^{\circ} \mathrm{C}$, and $450^{\circ} \mathrm{C}$ for 1008 hours. All the samples of MPDG $\left(Y_{1} G_{1} R_{1} D G\right)$ with diameter, thickness, and chromaticity coordinates were $15 \mathrm{~mm}( \pm 0.25), 0.5 \mathrm{~mm}( \pm 0.025)$, and $(0.36 \pm 0.005,0.29 \pm$ $0.005)$, as shown in Table 1.

Thermal aging tests were measured periodically in order to characterize the degradation of phosphor materials on lumen, CIE, and CRI. The data of all samples were obtained through the LED-645 test system (Lightports). The quantum yield (QY) is one of the major parameters used as a selected 
TABLE 1: High CRI sample counts of accelerated test.

\begin{tabular}{lcccc}
\hline Aging temperature $\left({ }^{\circ} \mathrm{C}\right)$ & 150 & 250 & 350 & 450 \\
Sample quantity $(\mathrm{pcs})$. & 11 & 11 & 11 & 11 \\
Chromaticity coordinates & $(0.35,0.28)$ & $(0.35,0.28)$ & $(0.35,0.28)$ & 15 \\
Diameter $(\mathrm{mm})$ & 15 & 15 & $0.35,0.28)$ \\
Thickness $(\mathrm{mm})$ & 0.5 & 0.5 & 0.5 & 15 \\
\hline
\end{tabular}

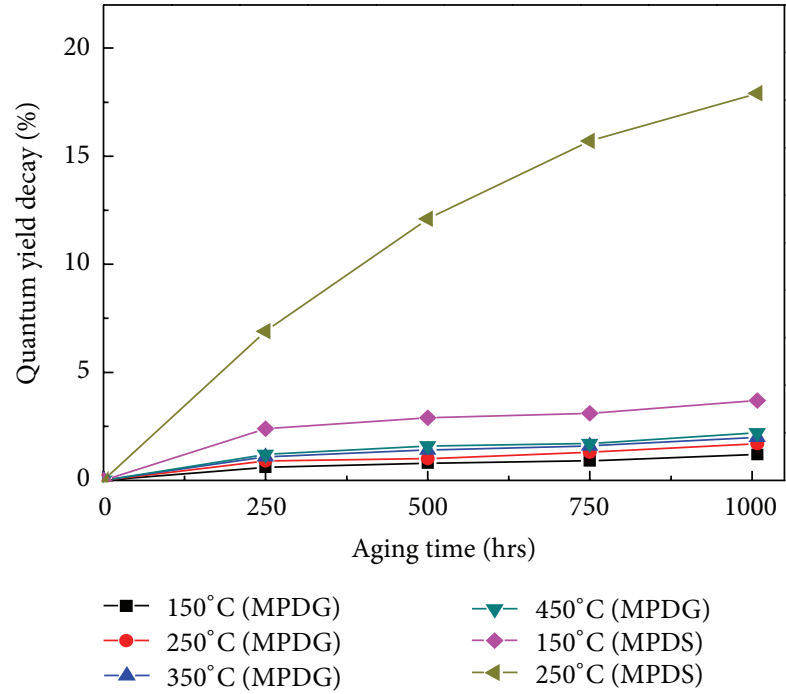

Figure 2: Quantum yield decay (\%) versus aging time for PCWLEDs of MPDG and MPDS samples at different temperatures.

criterion of luminescence materials in solid-state lighting applications, as shown in the following:

$$
\mathrm{QY}=\frac{N_{\mathrm{erm}}}{N_{\mathrm{Abs}}},
$$

where the QY of the wavelength converting materials is defined as the ratio of the number of photons emitted $\left(N_{\text {erm }}\right)$ to the number of photons absorbed from the emission of the pumping light sources $\left(N_{\mathrm{Abs}}\right)$, where the number of photons in each wavelength, $N(\lambda)$ (cps/nm), can be obtained through dividing spectrum distribution $P(\lambda)(\mathrm{mW} / \mathrm{nm})$ by photon energy $h \nu(J)[19]$.

CRI remanence is defined as the measured value of CRI after thermal degradation.

The chromaticity shift is defined as

$$
\Delta E=\sqrt{\left(u_{f}^{\prime}-u_{i}^{\prime}\right)^{2}+\left(v_{f}^{\prime}-v_{i}^{\prime}\right)^{2}+\left(w_{f}^{\prime}-w_{i}^{\prime}\right)^{2}}
$$

where $u^{\prime}=4 x /(3-2 x+12 y), v^{\prime}=9 y /(3-2 x+12 y)$ and $w^{\prime}=1-u^{\prime}-v^{\prime}$. The $u^{\prime}$ and $v^{\prime}$ are the uniform chromaticity coordinates [20], the $x$ and $y$ are the chromaticity coordinates (CIE 1931), and the $i$ and $f$ are the chromaticity shift before and after test, respectively. A schematic diagram of the test chamber for optical measurements is shown in Figure 2. The test chamber consisted of a $5 \mathrm{~W}$ GaN blue-light LED, a heat sink, a removable phosphor layer, and an integral

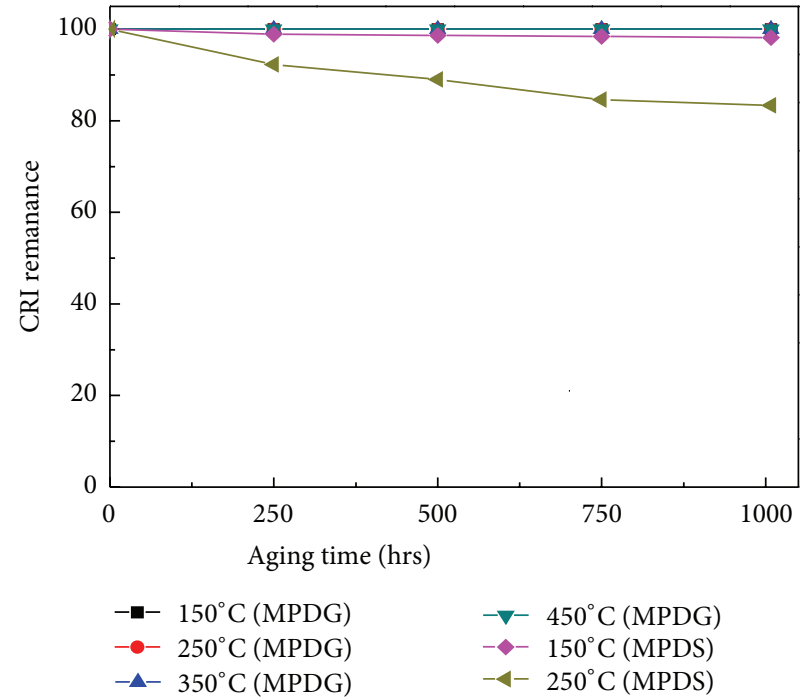

FIgURE 3: The CRI remanence versus aging time for PC-WLEDs of MPDG and MPDS samples at different temperatures.

sphere. LED and phosphor layer were integrated together. This setup is to ensure the thermal aging effect on phosphor layer after thermal aging tests that can be obtained precisely. Lumen degradation, chromaticity shift, and CRI loss at the wavelength of $460 \mathrm{~nm}$ were recorded and compared before and after each thermal test.

\section{Results and Discussion}

Table 2 shows optical properties of the WLEDs utilizing MPDG. The color coordinates and color temperature of the WLED utilizing Y1G1R1DG are $(0.358,0.288 ; 3923 \mathrm{~K})$ with high color rendering index up to 85 suitable for interior lighting.

3.1. Thermal Stability of High CRI Glass Phosphors. The thermal stability test results of both types of samples were carried out at $150^{\circ} \mathrm{C}, 250^{\circ} \mathrm{C}, 350^{\circ} \mathrm{C}$, and $450^{\circ} \mathrm{C}$ for 1008 hours. Due to silicone material carbonized above $280^{\circ} \mathrm{C}$, MPDS samples can merely be characterized under this temperature. Thus, MPDS can only be compared with MPDG below such critical temperature, while the characteristics of MPDG will be still presented at $350^{\circ} \mathrm{C}$ and $450^{\circ} \mathrm{C}$.

3.1.1. Quantum Yield Decay. To investigate the reliability of the high CRI phosphor with the glass and silicone, QY decay was measured as a function of aging time after thermal aging 
TABLE 2: Optical properties of MPDG based WLED.

\begin{tabular}{|c|c|c|c|c|c|}
\hline MPDG type & Top view & $\operatorname{CIE}(x, y)$ & CCT $(\mathrm{K})$ & CRI & QY (\%) \\
\hline $\mathrm{Y}_{1} \mathrm{G}_{0} \mathrm{R}_{0} \mathrm{DG}$ & & $(0.321,0.325)$ & 6043 & 68.58 & 68.36 \\
\hline $\mathrm{Y}_{1} \mathrm{G}_{1} \mathrm{R}_{1} \mathrm{DG}$ & & $(0.358,0.288)$ & 3923 & 85.25 & 55.57 \\
\hline $\mathrm{Y}_{2} \mathrm{G}_{1} \mathrm{R}_{1} \mathrm{DG}$ & & $(0.405,0.363)$ & 3248 & 73.96 & 59.40 \\
\hline $\mathrm{Y}_{1} \mathrm{G}_{2} \mathrm{R}_{1} \mathrm{DG}$ & & $(0.375,0.334)$ & 3803 & 81.25 & 55.31 \\
\hline $\mathrm{Y}_{1} \mathrm{G}_{1} \mathrm{R}_{2} \mathrm{DG}$ & & $(0.428,0.302)$ & 2182 & 70.16 & 47.24 \\
\hline
\end{tabular}

TABLE 3: Characteristics of MPDG and MPDS based WLED samples accelerated thermal aging after 1008 hours.

\begin{tabular}{|c|c|c|c|c|c|}
\hline Characteristics & Phosphor layer type & $150^{\circ} \mathrm{C}$ & $250^{\circ} \mathrm{C}$ & $350^{\circ} \mathrm{C}$ & $450^{\circ} \mathrm{C}$ \\
\hline \multirow{2}{*}{ QY decay (\%) } & MPDG & 1.2 & 1.7 & 2 & 2.2 \\
\hline & MPDS & 3.7 & 17.9 & N.A. & N.A. \\
\hline \multirow{2}{*}{ CRI remanence } & MPDG & 100 & 100 & 100 & 100 \\
\hline & MPDS & 98.2 & 83.4 & N.A. & N.A. \\
\hline \multirow{2}{*}{ CIE shift $\left(10^{-3}\right)$} & MPDG & 3.5 & 4.2 & 4.6 & 5.5 \\
\hline & MPDS & 10.1 & 151.8 & N.A. & N.A. \\
\hline
\end{tabular}

at 150 and $250^{\circ} \mathrm{C}$ for MPDG and MPDS shown in Figure 2, at measurement period 250 hours. After 1080-hour aging, the QY losses of MPDG were $1.2 \%, 1.7 \%, 2 \%$, and $2.2 \%$ at $150^{\circ} \mathrm{C}, 250^{\circ} \mathrm{C}, 350^{\circ} \mathrm{C}$ and $450^{\circ} \mathrm{C}$, respectively. The QY losses of MPDS were 3.7 and 17.9 times higher than MPDG at $150^{\circ} \mathrm{C}$ and $250^{\circ} \mathrm{C}$, respectively. MPDG samples maintained good thermal stability in QY characteristic.
3.1.2. Color Rendering Index Remanence. CRI remanence was measured as a function of aging time of the MPDG and MPDS after thermal aging at $150^{\circ} \mathrm{C}, 250^{\circ} \mathrm{C}, 350^{\circ} \mathrm{C}$, and $450^{\circ} \mathrm{C}$ at measurement period 250 hours shown in Figure 3. After 250-hour aging, the CRI remanence of MPDS was $98.2 \%$ and $83.4 \%$ at $150^{\circ} \mathrm{C}$ and $250^{\circ} \mathrm{C}$, respectively, while CRI attenuation was almost undetectable in the case of MPDG, indicating that 


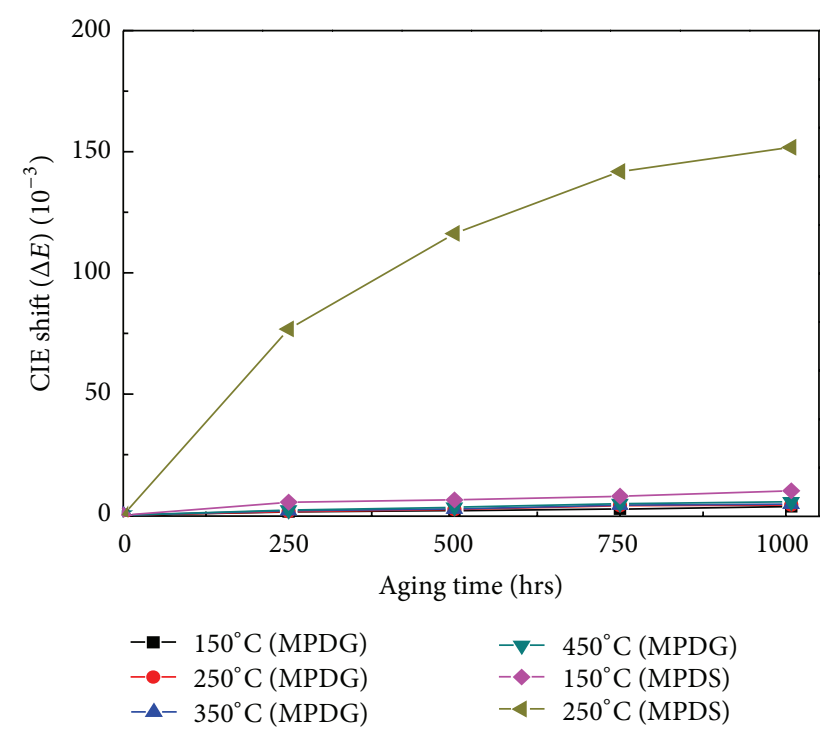

Figure 4: Chromaticity shift versus aging time for PC-WLEDs of MPDG and MPDS samples at different temperatures.

the MPDG samples maintained good thermal stability in CRI characteristic.

3.1.3. Chromaticity Shift. The chromaticity shift was measured as a function of aging time of the MPDG and MPDS after thermal aging at $150^{\circ} \mathrm{C}, 250^{\circ} \mathrm{C}, 350^{\circ} \mathrm{C}$, and $450^{\circ} \mathrm{C}$ as shown in Figure 4 for period of 1080 hours. The chromaticity shifts of MPDG were 3.2, 4.2, 4.6, and 5.5 all in the order of $10^{-3}$ at $150^{\circ} \mathrm{C}, 250^{\circ} \mathrm{C}, 350^{\circ} \mathrm{C}$, and $450^{\circ} \mathrm{C}$, respectively. After $1008 \mathrm{hrs}$ aging test, the chromaticity shifts of MPDS were $10.1 \times 10^{-3}$ and $151.8 \times 10^{-3}$ at $150^{\circ} \mathrm{C}$ and $250^{\circ} \mathrm{C}$, respectively. The chromaticity of MPDG samples was thermally stable than MPDS's.

3.1.4. Emission Spectrum. The emission spectrum was measured, with integrating sphere spectrometer, as a function of aging time for the MPDG and MPDS after thermal aged at $150^{\circ} \mathrm{C}, 250^{\circ} \mathrm{C}, 350^{\circ} \mathrm{C}$, and $450^{\circ} \mathrm{C}$, (a) and (b), respectively, shown in Figure 5. After industrial test standard 1008hour aging, better than MPDS's, all 4 samples of MPDG did not have significant intensity decay, as $2 \%$ and $3 \%$ at $150^{\circ} \mathrm{C}$ and $250^{\circ} \mathrm{C}$, respectively, less than $7 \%$ and $35 \%$ of MPDS, respectively. This indicates that the MPDG sample maintained good thermal stability regarding spectrum.

In Table 3, for both MPDG and MPDS, the accelerated thermal aging test results of QY loss, CRI remanence, and $\mathrm{CIE}$ shift were summarized as regarding aging temperature at $150^{\circ} \mathrm{C}, 250^{\circ} \mathrm{C}, 350^{\circ} \mathrm{C}$, and $450^{\circ} \mathrm{C}$. Due to a higher $T_{g}$ of glass matrix, it is also expected that internal strain is less in glass materials than in silicone under similar thermal stress owing to glass's lower thermal expansion coefficient. Since silicone matrix material tends to be carbonized by higher temperature aging [18], its thermal induced optical characteristic deterioration, such as CRI dropping, and so forth, will be prominent. These results showed that MPDG

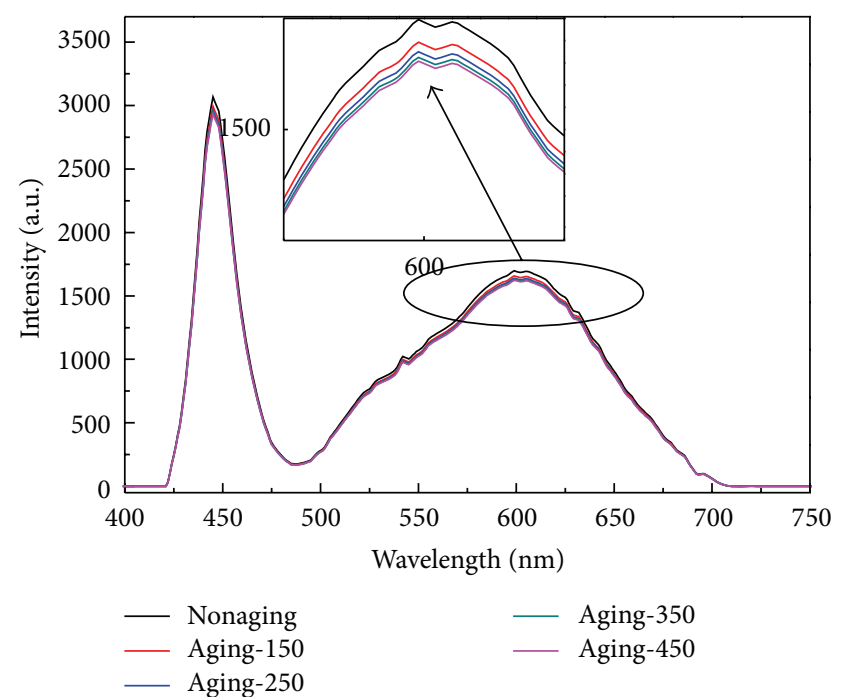

(a) MPDG

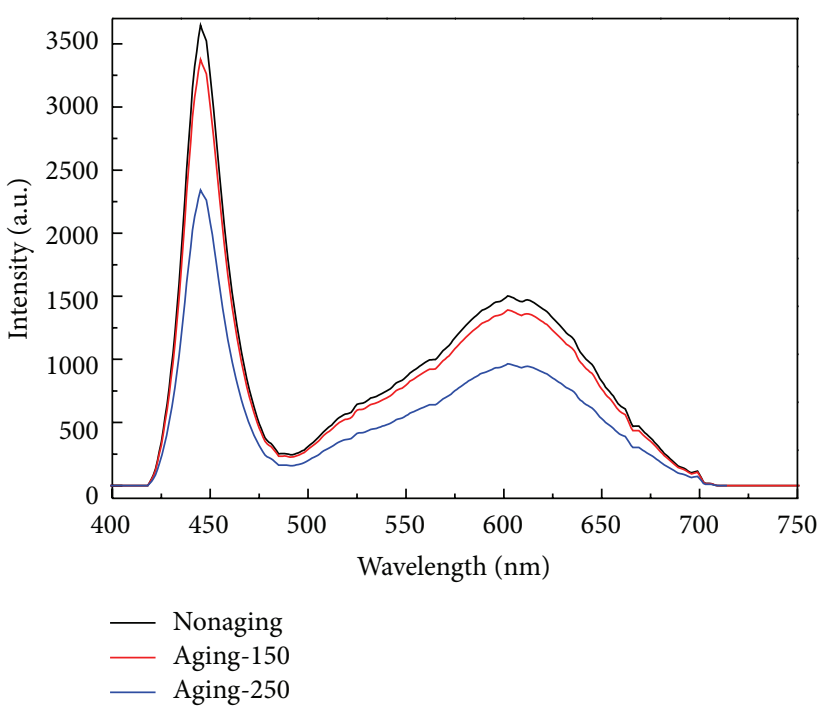

(b) MPDS

FIGURE 5: Emission spectrum versus aging time for PC-WLEDs of MPDG and MPDS samples at different temperatures.

phosphor conversion layer is effective for long-time hightemperature operation, and high CRI potentially for use in highly efficient and high output power LEDs.

\section{Conclusion}

The highly thermal stable phosphor-doped glass material has been successfully developed with both higher CRI and QY than those made of silicone. CRI remanence and CIE shift in glass-based high-power PC-WLEDs outperformed silicone base under thermal aging at $150,250,350$, and $450^{\circ} \mathrm{C}$ for industrial test standard 1008 hours. The results showed that the glass-based PC-WLEDs held better thermal stability in QY decay, CRI remanence, and chromaticity shift than the silicone-based PC-WLED, due to higher glass transition temperature $\left(T_{g}\right)$ of glass material property. More thermally 
stable phosphor layer of glass encapsulation material may be beneficial for many applications where LED modules with high power and high reliability are demanded for the nextgeneration solid-state lighting industry.

\section{Conflict of Interests}

The author declares that there is no conflict of interests regarding the publication of this paper.

\section{Acknowledgments}

This work was supported by the Science Park Administration under the Grant 102A10, the National Science Council under the Grants NSC 101-2218-E-269-001, NSC 1012622-E-269-020-CC2, and NSC 101-3113-E-110-002-CC2, and the Advanced Optoelectronic Technology Center, National Cheng Kung University, Taiwan.

\section{References}

[1] D. A. Steigerwald, J. C. Bhat, D. Collins et al., "Illumination with solid state lighting technology," IEEE Journal on Selected Topics in Quantum Electronics, vol. 8, no. 2, pp. 310-320, 2002.

[2] J. K. Kim and E. F. Schubert, "Transcending the replacement paradigm of a solid-state lighting," Optics Express, vol. 16, no. 26, pp. 21835-21842, 2008.

[3] M. R. Krames, O. B. Shchekin, R. Mueller-Mach et al., "Status and future of high-power light-emitting diodes for solid-state lighting," IEEE/OSA Journal of Display Technology, vol. 3, no. 2, pp. 160-175, 2007.

[4] S.-R. Lim, D. Kang, O. A. Ogunseitan, and J. M. Schoenung, "Potential environmental impacts from the metals in incandescent, compact fluorescent lamp (CFL), and light-emitting diode (LED) bulbs," Environmental Science and Technology, vol. 47, no. 2, pp. 1040-1047, 2013.

[5] J. K. Sheu, S. J. Chang, C. H. Kuo et al., "White-light emission from near UV InGaN-GaN LED chip precoated with blue/green/red phosphors," IEEE Photonics Technology Letters, vol. 15, no. 1, pp. 18-20, 2003.

[6] S. Muthu, F. J. P. Schuurmans, and M. D. Pashley, "Red, green, and blue LEDs for white light illumination," IEEE Journal on Selected Topics in Quantum Electronics, vol. 8, no. 2, pp. 333-338, 2002.

[7] K. S. Ramaiah, Y. K. Su, S. J. Chang, and C. H. Chen, "A comparative study of blue, green and yellow light emitting diode structures grown by metal organic chemical vapor deposition," Solid-State Electronics, vol. 50, no. 2, pp. 119-124, 2006.

[8] J. P. You, N. T. Tran, and F. G. Shi, "Light extraction enhanced white light-emitting diodes with multi-layered phosphor configuration," Optics Express, vol. 18, no. 5, pp. 5055-5060, 2010.

[9] R. Mueller-Mach, G. O. Mueller, M. R. Krames, and T. Trottier, "High-power phosphor-converted light-emitting diodes based on III-nitrides," IEEE Journal on Selected Topics in Quantum Electronics, vol. 8, no. 2, pp. 339-345, 2002.

[10] J. Zhang and N. Tansu, "Improvement in spontaneous emission rates for InGaN quantum wells on ternary InGaN substrate for light-emitting diodes," Journal of Applied Physics, vol. 110, no. 11, Article ID 113110, 2011.
[11] H. Zhao, G. Liu, J. Zhang, J. D. Poplawsky, V. Dierolf, and N. Tansu, "Approaches for high internal quantum efficiency green InGaN light-emitting diodes with large overlap quantum wells," Optics Express, vol. 19, no. 14, pp. A991-A1007, 2011.

[12] E. Rangel, E. Matioli, Y.-S. Choi, C. Weisbuch, J. S. Speck, and E. L. Hu, "Directionality control through selective excitation of low-order guided modes in thin-film InGaN photonic crystal light-emitting diodes," Applied Physics Letters, vol. 98, no. 8, Article ID 081104, 2011.

[13] Y.-K. Ee, P. Kumnorkaew, R. A. Arif, H. Tong, J. F. Gilchrist, and $\mathrm{N}$. Tansu, "Light extraction efficiency enhancement of InGaN quantum wells light-emitting diodes with polydimethylsiloxane concave microstructures," Optics Express, vol. 17, no. 16, pp. 13747-13757, 2009.

[14] R.-J. Xie, N. Hirosaki, N. Kimura, K. Sakuma, and M. Mitomo, "2-phosphor-converted white light-emitting diodes using oxynitride/nitride phosphors," Applied Physics Letters, vol. 90, no. 19, Article ID 191101, 2007.

[15] S. Nizamoglu, G. Zengin, and H. V. Demir, "Color-converting combinations of nanocrystal emitters for warm-white light generation with high color rendering index," Applied Physics Letters, vol. 92, no. 3, Article ID 031102, 2008.

[16] C.-C. Tsai, W.-C. Cheng, J.-K. Chang et al., "Ultra-high thermalstable glass phosphor layer for phosphor-converted white lightemitting diodes," IEEE/OSA Journal of Display Technology, vol. 9, no. 6, pp. 427-432, 2013.

[17] H.-C. Kuo, C.-W. Hung, H.-C. Chen et al., "Patterned structure of remote phosphor for phosphor-converted white LEDs," Optics Express, vol. 19, no. 14, pp. A930-A936, 2011.

[18] INTEMATIX Report, ChromaLit Remote Phosphor for Downlight Applications, 2013.

[19] S. Fujita, A. Sakamoto, and S. Tanabe, "Luminescence characteristics of YAG glass-ceramic phosphor for white LED," IEEE Journal on Selected Topics in Quantum Electronics, vol. 14, no. 5, pp. 1387-1391, 2008.

[20] J.-S. Wang, C.-C. Tsai, J.-S. Liou et al., "Mean-time-to-failure evaluations of encapsulation materials for LED package in accelerated thermal tests," Microelectronics Reliability, vol. 52, no. 5, pp. 813-817, 2012. 

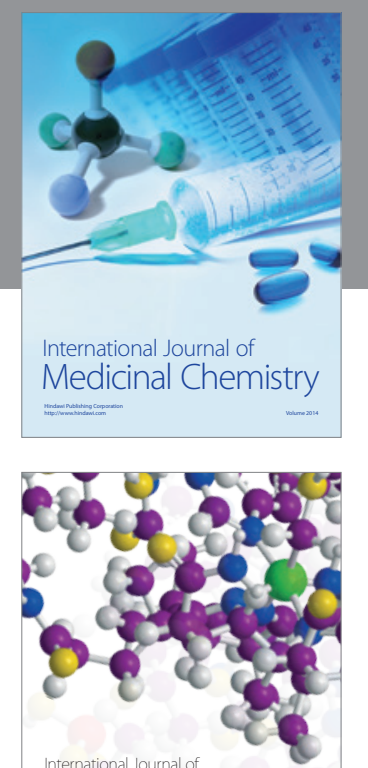

\section{Carbohydrate} Chemistry

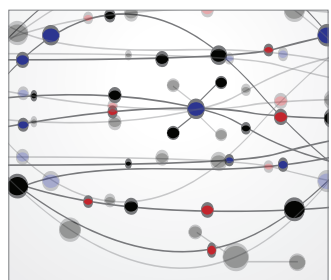

The Scientific World Journal
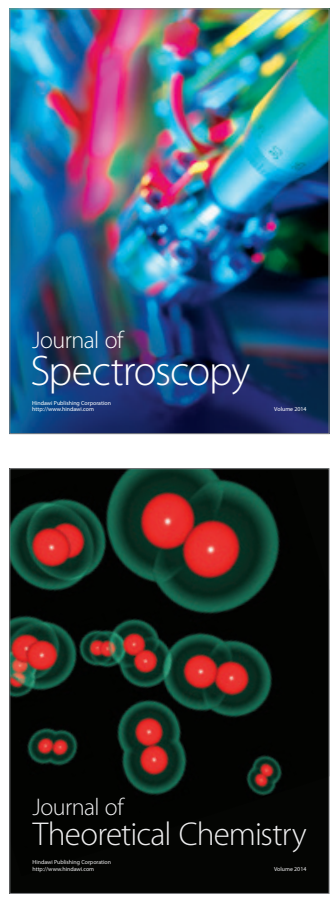
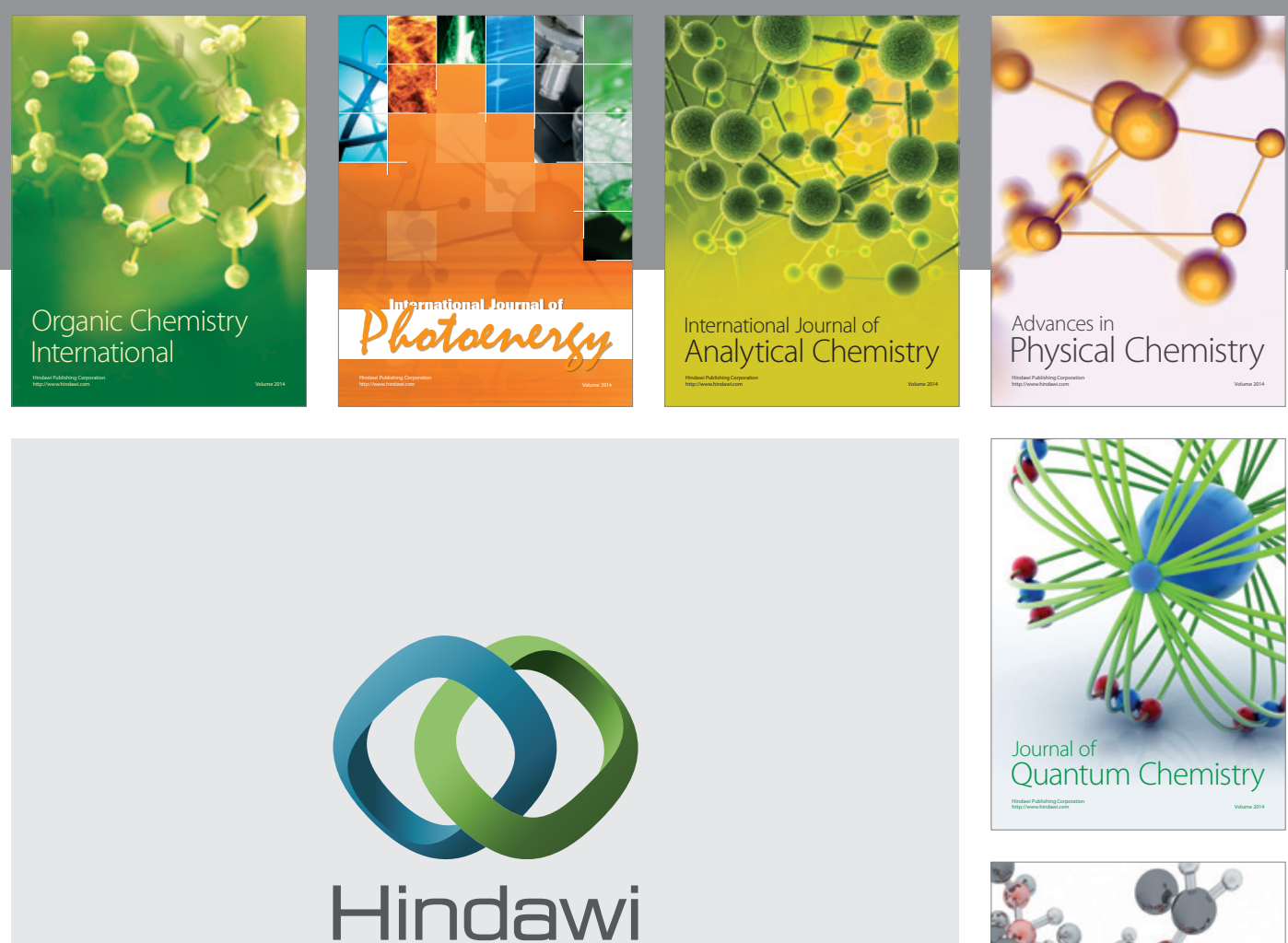

Submit your manuscripts at

http://www.hindawi.com

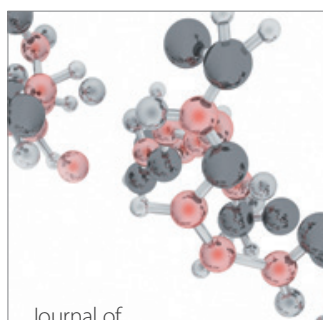

Analytical Methods

in Chemistry

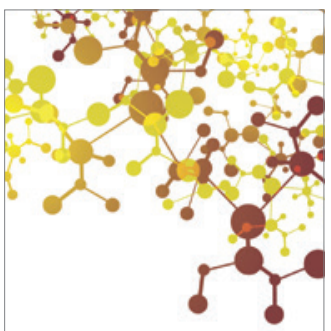

Journal of

Applied Chemistry

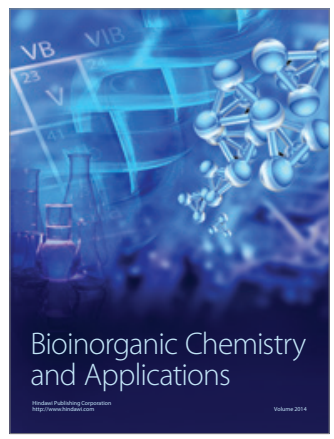

Inorganic Chemistry
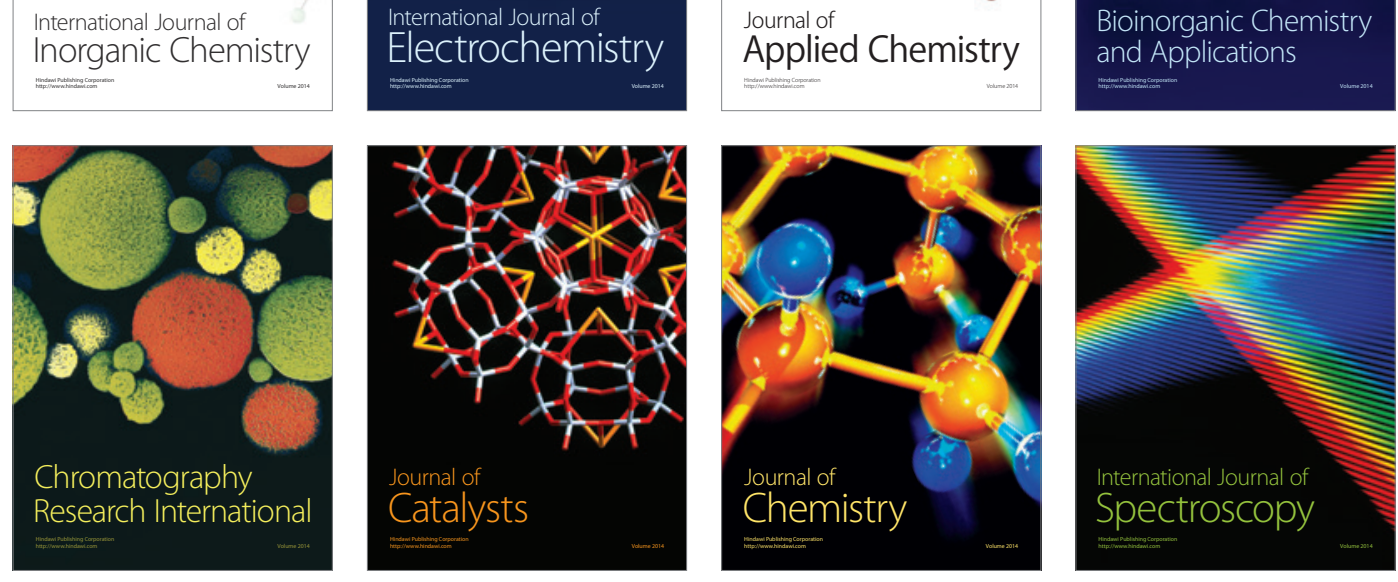